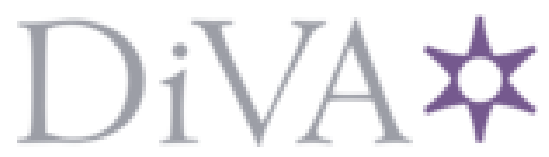

http://www.diva-portal.org

\title{
Postprint
}

This is the accepted version of a paper published in British Journal of Social Work. This paper has been peer-reviewed but does not include the final publisher proof-corrections or journal pagination.

Citation for the original published paper (version of record):

Addelyan Rasi, H., Moula, A., Puddephatt, A., Timpka, T. (2013)

Empowering single mothers in Iran: Applying a problem-solving model in learning groups to develop participants' capacities to improve their lives.

British Journal of Social Work, 43(5): 1-20

http://dx.doi.org/10.1093/bjsw/bcs009

Access to the published version may require subscription.

N.B. When citing this work, cite the original published paper.

Permanent link to this version:

http://urn.kb.se/resolve?urn=urn:nbn:se:kau:diva- 15688 


\title{
Empowering Single Mothers in Iran:
}

\section{Applying a Problem-Solving Model in Learning Groups to \\ Develop Participants' Capacity to Improve their Lives}

\author{
HamidehAddelyanRasi*, Linköping University, Sweden (hamideh.addelyan.rasi@liu.se) \\ Alireza Moula, Karlstad University, Sweden (alireza.moula@kau.se) \\ Antony J. Puddephatt, Lakehead University, Canada(apuddeph@lakeheadu.ca) \\ Toomas Timpka, Linköping University, Sweden (toomas.timpka@liu.se)
}

\footnotetext{
*Correspondence to Hamideh Addelyan Rasi,Division of Community Medicine, Department of Medical \& Health Sciences, Linköping University, SE-581 83 Linköping, Sweden,
}

Tel: +46-010-1037132, Fax: +46- 010-1031865, hamideh.addelyan.rasi@liu.se

\section{Short Biography}

AddelyanRasi holds her BA and MA in social work and at present she is a doctoral student at Linkoping University in Sweden. She has worked as a social worker for more than 12 years and has taught social work for more than eight years in Iran. Her research covers areas in social work, psychology, neuroscience, public health and sociology. She has published one book in community social work and some paper in social problems. She has completed several 
empowerment-oriented psychosocial intervention projects in Iran which are the basis for her present research.

Alireza Moula's research is located at the intersection of sociology, psychology, education science, social work, pragmatist philosophy, and neuroscience. Together with several other researchers, he has written a book in Swedish about empowerment oriented social work: $A$ Biopsychosocial Perspective (2009). He is the initiator and coordinator of a grand project that includes several research projects about empowering some groups of adolescents and women in Iran and Sweden. This grand project aims to create a neuropragmatist knowledge bank that integrates knowledge from pragmatist philosophy with neuroscience. Moula holds his BA and MA in sociology and his PhD in social medicine from Linkoping University in Sweden. He teaches sociology and social work and is assistant professor of social work at Karlstads University, Sweden.

Antony J. Puddephatt is an assistant professor in the department of sociology at Lakehead University, Canada. He is interested in sociological theory, pragmatism and symbolic interaction, science and technology, and ethnographic research. He is co-editor (with William Shaffir and Steven Kleinknecht) of a volume titled Ethnographies Revisited, which examines the practice of concept formation in ethnographic work through first-hand accounts of some of the most successful field researchers (2009, Routledge Press). He has published articles in journals including Social Epistemology, Sociological Focus, The Sociological Quarterly, Symbolic Interaction, The American Sociologist, Qualitative Sociological Review, and Studies in Symbolic Interaction. 
Toomas Timpka’s research has spanned from clinical social medicine and social work to health informatics and theoretical epidemiology. His present research interests include using ubiquitous computing technologies to support young people with mental disorders. He received his MD from Karolinska Institute, Stockholm, in 1983, and a PhD in Medical Informatics from Linkoping University in 1989. Between 1997 and 1998, he was a full professor of Informatics at Linkoping Institute of Technology. Since 1998, he is a full professor of Social Medicine and Public Health Sciences at Linkoping University, mainly teaching at the post-graduate level. He has published one book and more than 150 articles in scientific journals. 


\begin{abstract}
Since 2000, a problem-solving model has been taught to the Society for Protecting the Rights of the Child, and teachers and students of social work, in two universities in Iran. Since 2006, with the initiation of UNICEF, social workers, psychologists and even some psychiatrists in Iran have been learning this model. In 2008, a group of researchers created an empowerment-oriented psychosocial group and private intervention project to assess if a group of Iranian single mothers could use this model, which was traditionally used by professionals only, to effectively and independently meet challenges in their own lives. Our results show that all women used the model effectively, and consequently, made more deliberate decisions to improve their life situations. Some of the women succeeded in finding a job and many improved their family relationships. This study suggests that empowerment-oriented social work can help many clients to achieve their goals, and that this psychosocial intervention project can be a useful model for social work in Iran and many other societies.
\end{abstract}

Keywords: Iranian single mothers, psychosocial intervention, empowerment, capacitydevelopment, the Rahyab problem-solving model 


\section{Introduction}

Give a man a fish and you feed him for a day. Teach a man to fish and you feed him for a lifetime (Chinese proverb)

Is it possible to teach social work clients independent problem-solving methods that can be flexibly adapted to meet their life-situations? The traditional problem-solving method requires the practitioner to work through each problem with the client, implementing an expert model to work with clients to find the best possible solutions to problems in their lives. Recently, we have attempted to teach struggling Iranian single mothers how to use a well-developed problem solving model (named “Rahyab,” Persian for “finding one’s way”), independently, such that they can use it to meet any problems they encounter in their own lives. Rather than maintaining a dependency on the practitioner, this new approach is tailored to maximizing empowerment, autonomy, and self-direction in clients who face difficult circumstances on an on-going, day to day basis. Using this model that has been in professional use in Iranian social work environments since 2000, we wanted to examine how well ordinary citizens, in this case Iranian single mothers who are struggling personally, socially and financially, can implement the model in their everyday lives.

A person-in-environment formula (Moula, 2009; Moula et al., 2009) that outlines the psychosocial approach to goal-directed behaviour is presented to explicitly demonstrate the conceptual basis behind the problem-solving model of Rahyab (Fig. 1). A central tenet in this formula is that cognitive and emotional factors in the individual interact with environmental factors to determine the probability of achieving life goals. 


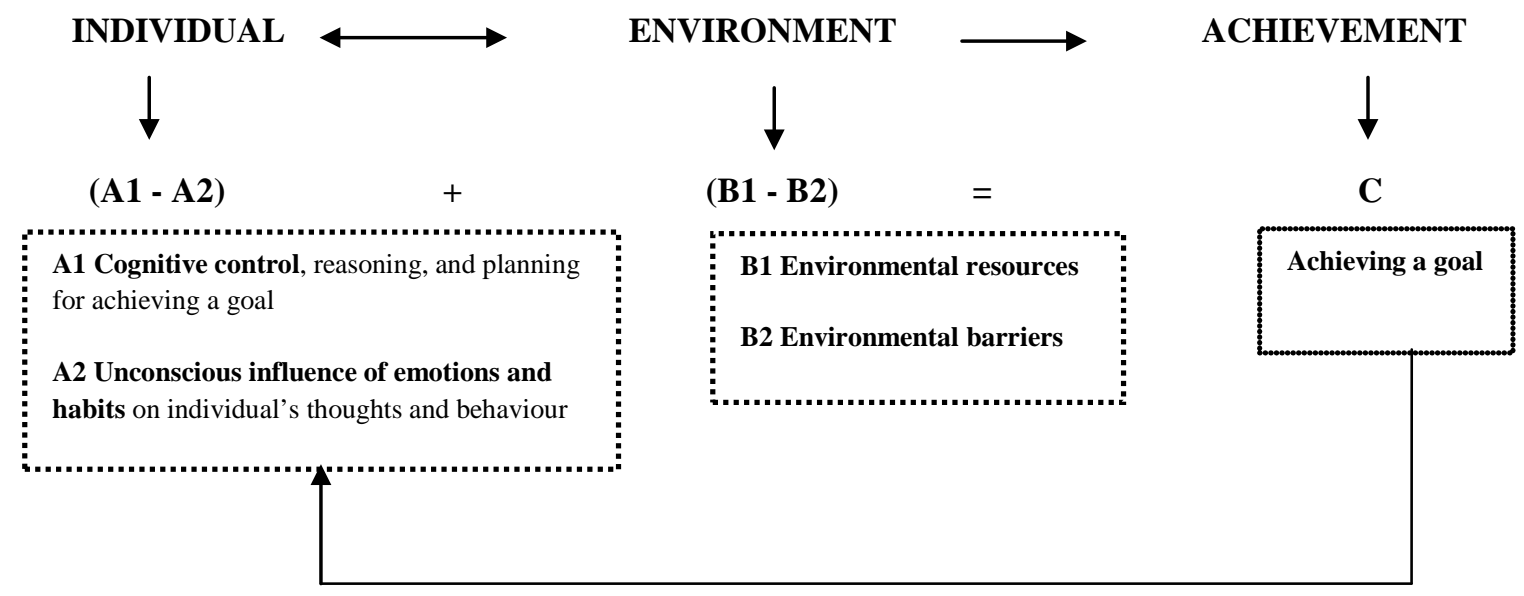

Fig. 1 Moula's person-in-environment formula

As neuroscientists Iversen et al. (2000) explain, emotions contribute to the richness of our experience and imbue our actions with passion and character. In line with recent discoveries of neuroscience we do not consider emotions as obstacles to rational thinking and decision-making. Virtually any cognitive performance is affected by a person's emotional status. A more biological scrutiny of the brain shows that some "brain areas are effectively nodes connecting regions that mediate emotional functions with brain regions that mediate other cognitive functions. The resulting interactions ultimately guide behaviour.” (Purves et al., 2008, pp. 455480) So, emotions and cognition do cooperate for proper behaviour and adaptation to the environment. From a cognitive control perspective emotional signals should operate "under the radar of consciousness,” and produce alterations in reasoning so that the decision-making process is biased toward selecting the action most likely to lead to the most desired outcome (Damasio, 2003, p. 148). Consequently, we assume that cognitive control constitutes the faculty for achieving life goals, but is often hampered by unconscious emotional distress and obstructive habits. This means that increasing cognitive control while consciously exploring one's emotions 
helps mediating their unconscious influence, increasing the ability to deal with environmental resources and obstacles, and more effectively achieve life goals.

Rahyab (see Table 1) had previously been applied in action-oriented research with Iranian families in Sweden (Moula, 2005, 2010). The aim of this study is to examine the experiences of social work clients in applying the Rahyab model independently, in an effort to solve problems encountered in their everyday lives. Learning spaces were created in order to develop Iranian single mothers' cognitive problem solving capacities and their ability to mobilize environmental resources. These learning spaces included group and private sessions that taught the Rahyab model.

Table 1 The Rahyab model

\section{Capacities to develop \\ Steps taken to engage in problem-solving}

\begin{tabular}{|l|l|}
\hline $\begin{array}{l}\text { To organize thoughts } \\
\text { and emotions through } \\
\text { story-telling or story- } \\
\text { writing }\end{array}$ & $\begin{array}{l}\text { 1. Define your situation and identify a problem. You may talk to a friend or a family member but YOU are the } \\
\text { expert of your own situation. You have lived your life and have experienced its "ups and downs". You may pick up } \\
\text { a piece of paper and a pen and describe the problem that mostly engages you. Simultaneously find out how your } \\
\text { thoughts and emotions are involved in the situation you try to define. It is also important that you consider your } \\
\text { relationships with significant others (family members, friends, etc.) who play an important role in your life and } \\
\text { especially in the situation that you want to define. }\end{array}$ \\
\hline strengths and & $\begin{array}{l}\text { 2. Identify (a) your desirable situation, (b) your strengths and (c) what is it in the problematic situation that } \\
\text { you want to change. Consider how your emotions/feelings are related to your desires. What do you feel when you } \\
\text { necessary changes } \\
\text { think about the changes that you wish to make? Consider your relationships with significant others. How do these } \\
\text { people affect your desires? When you think about necessary changes, what role can these people play in bringing } \\
\text { about these changes? You should also think about how these changes can affect the lives of other people. }\end{array}$ \\
\hline
\end{tabular}




\begin{tabular}{|c|c|}
\hline $\begin{array}{l}\text { To mindfully consider } \\
\text { various alternatives }\end{array}$ & $\begin{array}{l}\text { 3. Imagine and map several possible alternatives. Think systematically to find out which alternative may help you } \\
\text { move from the problematic situation toward the desirable situation. This includes thinking about (a) the possible } \\
\text { consequences of each alternative, (b) the resources that you can identify and use to realize the chosen alternative and } \\
\text { (c) the barriers that can impede each alternative (it is hardly possible to manage this step of the model without writing } \\
\text { your thoughts on paper). Consider: } \\
\text { - Your emotions/feelings in regard to these various alternatives. } \\
\text { How each alternative can affect the lives of others, and which roles others can play in realizing each } \\
\text { How are your values attached to different alternatives? It is crucial that you are aware how your values influence the } \\
\text { choice or rejection of any alternative. }\end{array}$ \\
\hline $\begin{array}{l}\text { To choose the best } \\
\text { possible alternative, } \\
\text { define a goal and plan } \\
\text { for action }\end{array}$ & $\begin{array}{l}\text { 4. Plan to realize your goal. Your goal relates to and gains strength from the desire that you identified in step } 2 \text {. } \\
\text { Now, after considering several alternatives (step 3) and in line with the possibilities of realizing each, you can choose } \\
\text { the best alternative and then formulate your goal accordingly. }\end{array}$ \\
\hline $\begin{array}{l}\text { To evaluate and learn } \\
\text { from the situation }\end{array}$ & 5. Evaluate the situation and learn from this for future actions \\
\hline
\end{tabular}

Table 1 Rahyab problem-solving model is constructed for use in empowerment-oriented intervention and social work practice (for the theoretical cornerstone as well as the development of this model through its implication in teaching, research and practice in Sweden and Iran see Moula, 2010, 2009, 2005, 2003).

In the section below, we present the conceptual background of two components of the Rahyab model: (1) the enhancement of individual cognitive resources and (2) the development of individuals’ social capacity to mobilize environmental resources. Thereafter, the empirical context of the study is introduced. 


\section{Human Capacity-Development: Learning Personal Problem-Solving Skills}

Several decades ago James Hayden Tufts (1917) introduced four factors as necessary to understand the nature of intelligent human conduct. He argued that humans beings: (1) are biological organisms with instincts and emotions necessary for survival, (2) are social as they enter into groups to communicate and cooperate, (3) have unique capacities for judgment and choice, and (4) develop their intelligence and reason through experience and the imagination. Similar to Tufts’ view of intelligent conduct is John Dewey’s understanding of human nature, which was based on the concept of change and development. Dewey (1922, p. 107) pointed out that "the human being differs from the lower animals in precisely the fact that his native activities lack the complex ready-made organization of animals’ original abilities.” Further, he indicates: "Native human nature supplies the raw materials, but custom furnishes the machinery and the designs” (1922, p. 110). Campbell (1996) summarizes Dewey’s ideas of human nature to state that people constitute a part of nature while they are also social and capable of abstract problem-solving. Perlman's model for problem-solving in social work was also influenced by Dewey's understanding of human nature and learning (Coady and Lehmann, 2008). She believed that learning a structured problem-solving approach could not only help clients to solve problems in the present, but also the future. Perlman integrated the diagnosis and treatment approach with a perspective that emphasizes starting where the client is in the present, partializing the problem into manageable pieces, and developing a supportive relationship between the client and social worker in order to strengthen the client's motivation, freeing their potential for growth. She assumed that many social work clients are in need of support to overcome social obstacles in order to improve their coping capacity (see Perlman, 1957, 1970). 
Pease (2002, pp. 135-136) refers to empowerment as “one of social work's key discursive practices,” and Spalek (2011, pp. 1662-63) indicates that “working towards empowering individuals and communities is, and should continue to be, a key goal for social work practitioners, educators and researchers, as well as others.” The concept of empowermentoriented social work can extend and complete Perlman’s problem-solving approach. Empowerment seeks to help clients gain the power of deliberative action by reducing the effect of social or personal obstacles, by increasing capacity and self-confidence, and by transforming power from the environment to clients (Payne, 1997). Empowerment-oriented social work can support individuals in discovering and developing their capacity to achieve client-defined goals (Moula, 2010, 2009, and 2005). In line with Coady and Lehmann (2008), we reject any approach that creates a dichotomy between a "problem focus” and a "strength focus" in social work practice. Due to the fear that emphasizing problem-solving can lead to a narrow focus on pathology and disorder in clients, some social work theorists (see Saleebey, 2006) try to use "the strength perspective,” but risk neglecting existing problems that clients may face that are in need of solutions. As we will show, it is quite possible to integrate these two perspectives, to use a problem-solving model in empowerment-oriented social work practice.

\section{Human Capacity-Development: Learning to Mobilize Environmental Resources}

Step three of the Rahyab model emphasizes on the individual's bond to her or his environment. Based on John Dewey’s differentiation between desires (step 2 in Rahyab) and goals (step 4), the model encourages clients to consider their desires (for Dewey [1938], the driving force behind realizing goals) as they are linked to their environment in an integrated way. The third and fourth steps attempt to connect the clients' desires to a concrete goal, look carefully into the 
environment to study available options, and choose the best line of action. In the words of Dewey (1922, p. 234), an ideal or a desire becomes a goal "only when it is worked out in terms of concrete conditions available” for its realization. There are considerable overlaps between Rahyab and many other problem-solving models, yet there are some important differences. Rahyab differentiates between desires and goals, and encourages clients to explore their emotions consciously and rationally, so as to help clarify desirable outcomes, and to manage them more effectively through the problem-solving process (for a comparison see Turner and Jaco, 1996; Zelazo et al., 1997; Coady and Lehmann, 2008).

\section{Single Mothers and the Organization of Social Work in Iran}

The number of single-mother households is growing world-wide (Dziak et al., 2010; Wang, 2004; Cairney et al., 2003; Brown and Moran, 1997) and Iran is no exception. According to the 2007 census, households with a female head (single mothers) constituted 9.4\% of all households in Iran, up from 8.4\% in 1997, 7.3\% in 1987, and 7.1\% in 1977. From 1997-2006, the number of households with a male head increased by 38\%, while households with a female head increased by 58\%. More than $60 \%$ of single-mother households in 2001 did not have any income from a job, or support from other family members (Statistical centre of Iran, 2011). As a result, it was estimated that $88.2 \%$ of single mothers were supported by social welfare organizations in Iran at that time.

In Iran, trained social workers in different organizations have the aim of supporting individuals, groups and communities in the face of growing trends of social and economic pressures that have the greatest effect on vulnerable populations. The main organizational actor is the governmental social welfare office (called Behzisti), which attempts to increase people’s well-being in society. Behzisti includes a division called "Women and family.” Single mothers 
constitute the most important client group for this division. Within the last five years, this division has emphasized empowering clients by teaching life skills, entrepreneurship, and family management (Behzisti’s instructions, 2008/2011).

\section{Methods}

A descriptive field study design (Heppner et al., 2008) was employed to investigate an empowerment-oriented psychosocial group and private intervention based on the Rahyab model. A content analysis was performed on data collected from participants during and after the intervention. The research had a strong participatory character. The planning of the intervention sessions was performed by the first author and the participating women, and the data for the evaluation of each session and the entire intervention was provided by the participating women. The first author contacted the Behzisti organization in a large urban area in Iran, and described the project, asking for help in inviting study participants. The criteria for being invited to the study were being a single mother, living in poverty, having requested social assistance, and not having significant medical, mental or substance abuse problems. Behzisti referred the first author to three separate offices that introduced her to 16 women fulfilling the study inclusion and exclusion criteria. The first author arranged a meeting with these women, and explained the procedure and aims of the intervention project to them in detail. Fifteen of these women announced their consent to participate in the project. All of these fifteen women signed an ethical consent form and agreed to participate in both group and private sessions (table 2). Pseudonyms were used throughout to protect anonymity and confidentiality. Researchers at Linköping University, Sweden, are responsible for safeguarding the gathered data. The project has received ethical clearance from the first author's home institution. 
Table 2 Sociodemographic characteristics of the project participants $($ Number $=15)$

\begin{tabular}{lc}
\hline & Number \\
\hline Age & 6 \\
$27-33$ & 9 \\
$34-48$ & \\
Education & 5 \\
Primary school $\leq 5$ years & 5 \\
Primary school 7-8 years & 5 \\
High school Diploma & \\
Work situation: & 9 \\
Part time or temporary employment & 6 \\
No employment & \\
Children (number) & 8 \\
1-2 & 5 \\
3-4 & 2 \\
5-7 & 2 \\
Housing situation & \\
Independent house & 5 \\
Living with parents & 10 \\
Reason for being single mother & \\
Divorce due to husband's addictions & 8 \\
Divorce for other reasons & 5 \\
Death of husband & 2 \\
\hline
\end{tabular}

The intervention project started in May 2008 and ended in November 2008. Both private and group sessions employed Rahyab and took place in parallel. The first author put in approximately ten hours a week over a period of seven months, amounting to over three hundred hours of intervention. In the private sessions, Rahyab was used as a tool—a problem solving model — to help meet the difficulties that the participants had chosen to discuss, within an empowering dialogue maintained between the social worker (first author) and the participant. Through such meetings, participants learned to organize their feelings and thoughts through storytelling and discussing desirable changes (steps 1 \& 2). Later, the dialogue between the two experts - the social worker who employing/teaching Rahyab and the participant who discussing her own life_-continued with the aim of finding possible alternatives for action (step 3), and developing concrete plans on that basis (step 4). Participants were encouraged to take a paper and pen and continue to think and write about their problems and possible solutions while following the steps of the model at home. 
Group sessions were offered once a week in order to teach participants reflective thinking and how to better mobilize environmental resources. In total, nineteen group sessions were arranged. In these, the participants used Rahyab to solve fictive problems/scenarios that were suggested by the participants themselves. A form was distributed in the beginning of the sessions, and participants had 15-20 minutes to write down what they thought about that problem/scenario. For example, one question asked "What would you do if you found out that your teenager has an addiction?” Later, participants presented their ideas, and based on what each had written, a discussion took place. This method helped each participant to think individually and be ready to discuss her own ideas with others. At the end of both private and group sessions, each participant wrote or talked about "what I have learned from this session.” Since three of the women could not write well, a secretary or the researcher/social worker would write down what the women said. All of the women's evaluations were collected and used for analysis.

Additional data were collected at the end of the project (after seven months), when all mothers were asked to evaluate their achievements and state what they had learned. We were interested in the extent to which these single mothers used what they had learned after the project. All fifteen women provided evaluation data directly at the end of the project, and nine women contributed data seventeen months after the end of project. We performed a two-step analysis. We started with a conventional content analysis (Patton, 2002) and described what happened during the project and how it may have influenced the women. The two researchers well versed in Persian initiated the process by reading through the entire set of data transcriptions in their native language to uncover and discuss the key preliminary themes. This was done to identify ideas grounded in the language of the participants. We then used open coding to break 
down, investigate, compare, conceptualize and categorize the data. The same two researchers then coded the texts separately, and then compared their results. This process continued until both researchers were satisfied with the joint coding scheme, and agreed that it covered the issues found across the entire data set.

Later, we used the person-in-environment formula to examine the participants’ postproject achievements. We coded the data into three major categories: individual capacities, environmental capacities and achievements. We then used an inductive within-category coding of the data to identify these themes. In addition to this qualitative content analysis, we also collected supplementary quantitative data on the intervention outcomes, which counted the number of women represented in each of the achievement categories.

\section{Results}

All fifteen women completed the project and, to varying degrees, utilized Rahyab effectively in their daily lives. The analysis displayed three life-management areas where capacities had developed during the project, and three concrete areas of post-project achievement. Below, we present the development of each life-management area in some detail, and then outline the postproject achievements that the women reported on.

\section{Areas of Life-Management through Learning}

Developing Problem-Solving Skills for Self-Management

All participants reported how they had learned to think more reflectively during the project.

Some had succeeded in better controlling their emotions and behaviour, while others learned to see the world from a new perspective. Below, we illustrate these types of changes through two 
cases. Poneh, a 27-year-old woman with two children had severe problems. She "married with a 92-year-old man in order to have a place to live.” However, this marriage could not help Poneh's family for a long time and soon she was on her own again. She borrowed money from Behzisti to use it as capital to find work. Once, Poneh was deceived by a man who told her he could use her money as capital, giving her a good investment rate. After a while the man completely denied that he took money from Poneh. One day, she met the man on the street and attacked him, damaging his car. Poneh was called to court as a result of causing this damage. After she joined the project, her aggressive behaviour improved. When she went to the court, she remained calm and apologized for her behaviour; as such, she was forgiven. While Poneh has seen much injustice in the world, and her anger is understandable, she has learned that violence only makes her family's situation worse. Poneh indicated that she has learned to think more deliberatively before immediately reacting, and reported that before joining this project "I created $90 \%$ of my own problems.” She also added that “before this project I had suicidal thoughts but now I realize my own value.” Poneh also refers to her temperament when she indicates that "Earlier I talked before thinking, but now I do not talk quickly and do not become angry. Even if I become mad at someone I think before talking or acting.”

Another participant, Laleh, who married at 16, explained that her marriage had progressively turned her into a passive person: "My husband always tried to solve problems himself... He took care of our affairs outside the home and I was a house-keeper... As a result, I did not know anything about how to meet problems when they happen.” However, Laleh’s husband was killed in an accident and Laleh became very sad and confused. After joining the project, Laleh explained, she realized that applying Rahyab to her problems was just what she needed as a complement in her life. In the beginning, she found Rahyab difficult to understand, 
but gradually she learned how to use it. By developing these acquired skills, she was better able to logically explore her life problems by writing down their possible consequences, and checking whether her anxiety was proportionate to the facts. Even though the problems did not go away entirely, Laleh was able to reduce her worries: "Before the project, I thought my problems were the biggest problems in the world, occupying my sleep and waking time. When I learned the five steps of the model, and wrote the problem on paper, seeing it in only a few lines of text, I became calm... This was the best way to approach problems that I have ever learned...”

\section{Learning to Manage the Family Economy}

When these women joined the project, thirteen of them were receiving money from Behzisti. Maintaining the family economy was a major concern for all these single mothers. A related problem was that many of these women could not afford their own apartments, and had to live with their relatives. We illustrate participants' development of their life-regulation through the story of Maryam, who is 46 years old, has two children and only five years of primary education. She started to work as a barber but since then she had trouble standing for long periods, so she left that job. After her separation, Maryam lived with her parents. Since she did not have an apartment or a job, and was dependent upon her father, her sisters and brothers did not respect her. She experienced physical pain, depression, and used medicine to cope.

After she joined the project, Maryam used Rahyab in private sessions to manage her situation. Step one of the model helped Maryam to understand that financial problems breed many accompanying psychological problems. The second step indicated a desire to find a job. Through the third step, she thought of several alternatives: (1) to start a small shop to sell cloth alone, (2) to do the same together with a partner, and (3) to start a small barber shop. She 
investigated resources and barriers against each of these alternatives. Many shop-keepers warned her of the difficulties of running a shop. During this investigation, however, she learned about another option. She found that some women travel to a border town and buy clothes to sell them in big cities. She chose this alternative, got some financial support from Behzisti as primary capital, and started the business.

\section{Learning to Manage Family Relationships}

The third area where life-regulating capacities were developed was with regard to family relationships. We present two of the cases to illustrate this category. Susan was 36 and has two daughters. She gradually discovered that her husband's behaviour had changed. Below, we present a summary of her narrative:

\footnotetext{
My guess was correct, what I was afraid of happened. Addiction, a great problem that destroys families... What should I do, now with two children...? I loved my husband and was ready to do anything to help him and keep our family. His behaviour became more and more strange and I could not tolerate him anymore. I decided to separate even if I loved him... I went back to my father’s house... I was depressed and angry, and I punished my child... I felt that I was not able to do anything... Joining this project helped me to learn to live and learn how to interact better with my children. My first child had lots of psychological damage. There was a gap between us that was increasing more and more (Susan).
}

As a participant of the project, Susan got "new hope and started to understand what life is about.” Through private and group sessions, Susan learned to apply Rahyab to improve her relationship with her first daughter. Susan realizes that she should start by modifying her own behaviour, remaining calm and patient, and not shouting at her child. She says that the calmer 
she became, the better she could interact with her children, and they would become calm in turn. "With the help of the model I could embrace my problems and try to solve them. Last night my daughter and I talked and listened to each other. I was waiting for this moment for several years.” This relationship with her daughter was so important to Susan that she often refers to this moment as her "rebirth."

Mikhak, 39, lived with her handicapped 23-year-old daughter (Sara). After entering the project, Mikhak used Rahyab to describe her relationship with Sara: “Sara makes me very anxious, does not move and lies in place all the time. I have to do all her work... I feel responsible about her behaviour... I did not let her accept responsibility for her own behaviour so that she could learn to do things on her own.” During later private sessions, Mikhak discussed her relationship with Sara: "I have learned how to talk to her, how to judge her behaviour, and what to ask her to do or not to do.” Through private sessions she learned to control her emotions and frustrations, and improved her relationship with her daughter.

\section{Post-Project Capacities and Achievements}

\section{Individual Capacities}

After the project, all fifteen women had demonstrated the ability to learn Rahyab to enhance their reasoning in life-management. In this context, emotions were considered as resources, rather than as barriers to rational thinking. For example, Hortensia wrote that she started to become aware of and try to control her emotions and habits. She added that "we have to consider and be critical about the style of our thinking." Susan wrote that "I have to be patient in meeting problems. Problems always exist in our lives. I should meet these problems with the help of the model, stop for a moment, think, and then act.” Laleh considered both her emotions and what 
she called "deep thinking”, and indicated that when she is conscious about her emotions, she can regulate them and make better decisions. She wrote about fostering positive habits of mind when she said "I should use this model in my life all the time until it becomes internalized, in the same way that I know $2 \times 2=4$ without much thought.” Rose indicated that it is difficult to change bad habits, however, she is conscious that she has to change these bad habits in order to live a better life. Rose is cognizant that she needs to think about changing herself in different situations, and consciously follow explicit reasoning in meeting her problems. Yasaman classifies the process of her thinking and problem-solving in the following words: to express my problems, reason toward finding solutions, look at problems from several views, be hopeful that there is a solution, and finally, to be thoughtful and "with patience, unlock the puzzle.”

\section{Environmental Capacities}

Fourteen of the mothers emphasized that the group sessions played a vital role in both learning the model and using it, claiming that these gatherings became a strong source of environmental support. For example, Yasaman wrote: “I learned from other women’s experiences what I could not personally experience and got some answers to the questions that I had. I happened to meet women who all had the same problem — being a lone parent—and so we all had to be lone problem-solvers.” Hortensia wrote that the women became like members of a family, with a special empathy and sympathy for each other. These women experienced the group sessions as helpful and wished that it could continue. Poneh wrote that in the beginning she was not sure that these sessions would help her. However, now she is ready to take off from her work, once a week, eagerly joining these group sessions. Group sessions were not the only external resources for these women. Some mentioned that their family members, or the services provided by 
Behzisti, were also important. Mina indicated that her son was a resource for solving her daughter's problems. Being young, he could better understand her sister and her situation. Hortensia also mentioned that her children could sometimes better understand the family situation, and help her with chores through a division of labour. Mina got financial support from Behzisti and started a small private sewing business. Zanbagh received some financial support in order to help her daughter marry.

\section{Achievements}

The single women reported that their main post-project achievements were reached with regard to self-management, social relations, and the family economy (see table 3). All participating women, albeit in varying degrees, demonstrated an improved self-management and enhanced well-being. They had changed their patterns of thinking, which in turn led to better control of their emotions and behaviour. For instance, Susan talked about her lack of self-confidence before the project in regards to her job and said "I lost two kilos of my weight whenever I wanted to deliver ready-made clothes to my clients.” Now "I have better self-confidence,” and work calmly and with better results. Hortensia concluded that "we all reach a state of serenity and hope.” Banafsheh indicated that "I have improved my self-confidence and have more serenity.” She meant that some of the ideas of Rahyab already exist in the mind of people, but not in the systematic order presented in the model. She added that when she used a paper and pen, she could think better. Banafsheh concluded that in general, using the model's different steps helped her to remember important issues while working through problem solving situations. From the thirteen women who started the project with financial support from the welfare office, seven became independent after the project concluded. Banafsheh concluded that 
she was better at her work and stated that "I have more clients." Yasaman, who lost her job, was now working with a child with disabilities, and came to the conclusion that with the help of others, she would start a day-care for children with special needs. Eleven of the women also reported improving their family relationships significantly. For instance, Hortensia indicated that "My children and I have learned to plan for our activities. Our relationships have improved.” Susan has radically improved her relationship with her daughter, as reported earlier. Mina added that before the project "I imposed my will on my children. Now, I try to understand what they want.” Hortensia gives a concrete example of her relationship with her son: "Before working with this model I was completely confused and did not know what to do with him and his problems. After applying this model, I have reached some solutions and consequently feel a kind of serenity... In a friendly space I give my son the chance to communicate and talk and try to find a solution himself... I no longer lose my temper and try not to put my interpretations in place of his thoughts... I owe this achievement to the model especially.”

Table 3 Post-project achievements of the single mothers in fields of economy, relationships and self-management

\begin{tabular}{|c|c|c|c|c|}
\hline & Economy & Relationships & Self-management & All achievements \\
\hline Laleh & * & & * & 2 \\
\hline Susan & & $*$ & * & 2 \\
\hline Hortensia & & * & $*$ & 2 \\
\hline Narges & & $*$ & $*$ & 2 \\
\hline Rose & $*$ & & $*$ & 2 \\
\hline Poneh & $*$ & $*$ & $*$ & 3 \\
\hline Orkideh & & $*$ & $*$ & 2 \\
\hline Mikhak & & $*$ & $*$ & 2 \\
\hline Zanbagh & & & $*$ & 1 \\
\hline Aghaghia & $*$ & $*$ & $*$ & 3 \\
\hline Mina & $*$ & * & * & 3 \\
\hline
\end{tabular}




\begin{tabular}{lcccc}
\hline Maryam & $*$ & $*$ & $*$ & 3 \\
Yasaman & & $*$ & $*$ & 2 \\
Banafsheh & $*$ & $*$ & $*$ & 3 \\
Shaghagia & & & $*$ & 1 \\
\hline All women & 7 & 11 & 15 & 33 \\
\hline
\end{tabular}

\section{Discussion}

The aim of this study was to explore the experiences of Iranian single mothers as they learned and implemented the Rahyab model to solve day to day problems, and assess how well the model helped to enhance the women's problem-solving skills as well helping to create concrete achievements in their life situations. Figure 2 summarizes the relation between the structure, process and outcome of the intervention project. All women completed the intervention and demonstrated an improvement in their reasoning toward more reflective and deliberative thought. They learned to better connect with and regulate their emotions, which helped to clarify their desired goals and better identify the role of their emotions in the problem-solving process. A majority of the women improved their family relationships, and almost half had improved the financial situation of their family.

Inspired by John Dewey, we started from the premise that all humans have the capacity to act intelligently, yet all can benefit by improving habits to enhance reflective thought. We oppose the notion that certain categories in a population are inferior in their learning abilities due to their social or cultural belongings. None of the women in this sample had a university education, some had difficulties in writing, and three needed a secretary to write for them. Nonetheless, they still managed to learn to use Rahyab effectively to enhance their reasoning capacities and better confront problems in effective ways. Dewey trusted the capabilities of all 
human beings, put faith in the possibilities of human nature, and believed in the unique qualities and strengths of individuals to marshal intelligent judgement and action insofar as the proper habits for reflective thought are nurtured and allowed to flourish (Campbell, 1996).

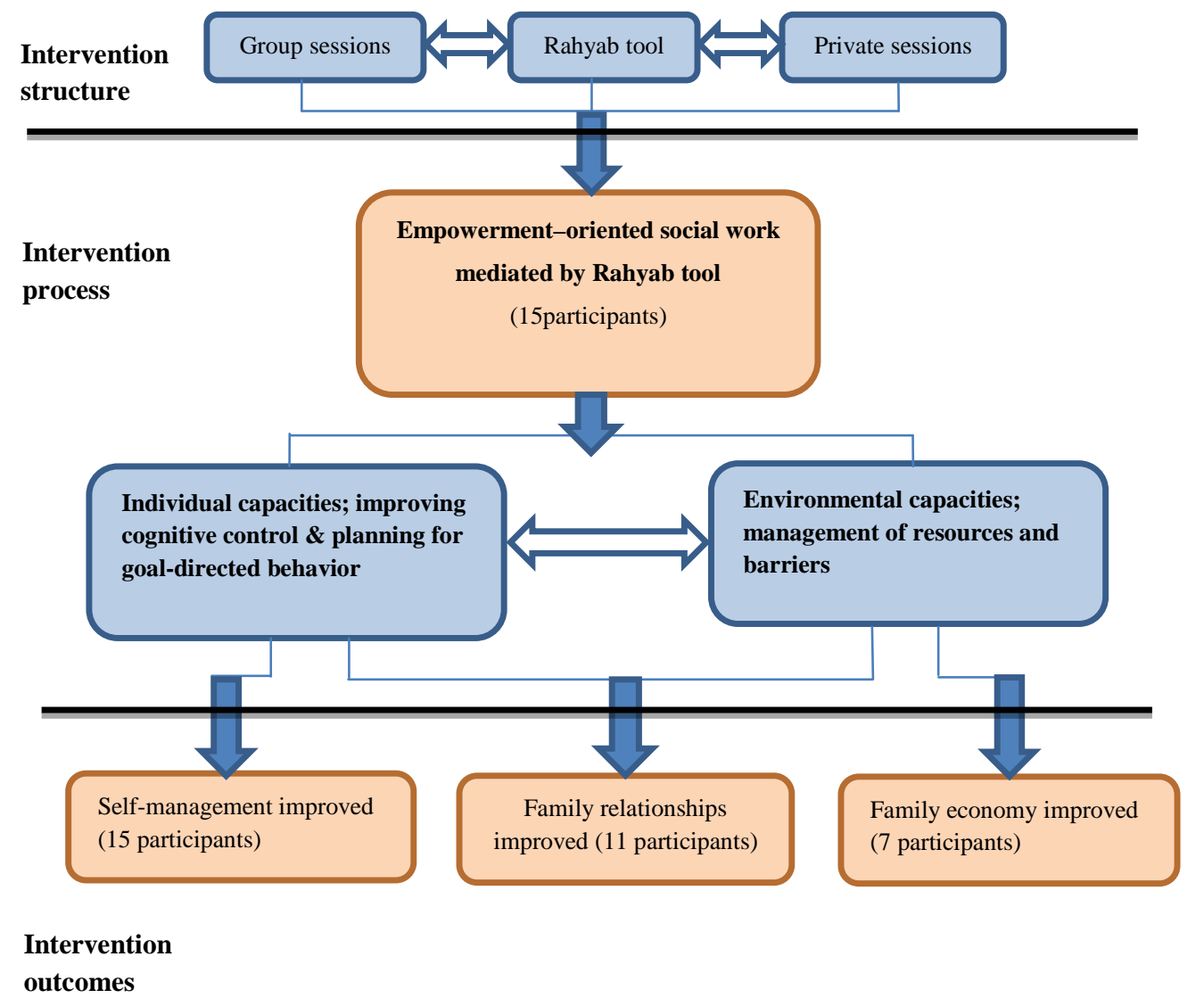

Fig. 2 The relation between structure, process and outcome of intervention

The methodological strengths of this study included prolonged engagement with the clients and persistent observation with the intervention process, which enhances the validity and credibility of our findings. This was accomplished by dedicating enough time for the gathering of data and the in-depth process of coming to understand the participants' experiences, which occurred over seven months in both private and group sessions. Our methods are limited in that 
the research was based on a combination of group and private sessions, so we cannot study what would happen if we only used one intervention strategy. Another limitation is that since we were not dealing with a large group of clients, and thus, had a smaller sample, we could not make strong conclusions about the relevance of different demographic criteria, such as the participants’ socio-economic background. We present this data mainly as indicative and suggestive of potential patterns, not as determinative or final.

As the participants emphasized, training was necessary for learning and using the Rahyab model effectively. For example, Laleh indicated that she taught it to her relatives partly because within that process, she could learn more about how Rahyab works. To paraphrase William James (1907), the women successfully integrated old opinions with new ones. To understand such a process of change can be a long and hard task. However, in social work this is crucial, as an unrealistic expectation of rapid changes in thinking, and consequently, emotions and behaviour, can lead to failure and discouragement. More research is therefore needed to better understand how to develop effective training strategies to teach Rahyab to different client populations in social work practice.

The second factor contributing to the women's achievements was that the proper conditions for development had been established. These conditions were composed of three complementary elements. Rahyab provided the content of the group sessions, where the women discussed and solved fictive scenarios. It was applied to their real problems in private sessions with the first author, and it was used to help reorganize the women's habits of mind in both the group and private sessions. Our three mutually supportive activities - the use of Rahyab, private sessions and group sessions — could also be effective for other social work clients, especially if 
the participants have something in common. For example, the model could be utilized effectively to help the unemployed, parents with disabled children, etc.

Several points need to be considered before trying to implement the current intervention in other settings. Two conditions seem necessary if the intervention is to be successful: (1) social workers should go through a short intensive course to learn to work with and teach the model effectively; and (2) social workers should create effective learning spaces, making use of group and private sessions, for their clients. The first condition is relatively simple, but the second is more demanding. The first author put approximately ten hours a week in a period of seven months for this project. Do social workers in different countries get such an opportunity for this kind of commitment? At the same time, we should not forget the by-product of this intervention project. Some of these single mothers are now trying to teach the model to their relatives and friends. Thus, the actual number who learn and use the model can go beyond those participating in the project. This is another reason why putting these types of capacity-building projects into action may have positive effects that go well beyond our immediate sphere of influence.

Regarding psychosocial interventions designed to help women who are deprived of basic resources, other studies suggest that mediating such initiatives with a learning tool can help foster positive cognitive changes (Daher and Haz, 2010). The strength of our intervention was that it equipped clients to cope more effectively with the difficulties they will encounter in the future. A major advantage of learning problem solving skills is that the principles can be transferred from one situation to another. As a group of social work practitioners and theorists (Hepworth et al., 2002, pp. 399-400) indicate, “many social workers have difficulty delineating precisely the elements of independent problem solving.” In line with these authors, we propose 
that social workers engage in both processes, thereby seeking not only to remedy immediate problems but also to enhance clients' future coping capacities.

\section{Conclusion, Implications, and Questions for Further Research}

Performed in Iran, this study demonstrates that a group of single mothers benefitted greatly by learning and implementing a problem-solving model to independently meet the problems of their daily lives. The result of our study suggests that these goals are quite achievable and that this project can become a model for social work if social workers get the chance to implement such psychosocial interventions. The intervention in Iran included three parts; private sessions, group sessions, learning and using an empowerment-oriented problem-solving model. First, it should be noted that none of these three practices is especially Iranian. Private sessions with clients are common practice in social work. Group sessions for clients who share the same challenge are also common. Further, the Rahyab model, which was first constructed and used in Sweden, has much in common with many other problem-solving models in social work. However, creating learning spaces with group and private sessions while teaching an empowerment-oriented problem-solving model for independent use is a novel approach, and this project in Iran has shown that it was successful.

Scrutinizing this intervention in Iran raises some important questions about what in social work practice and policy is local and what is universal. Can the success of this project be deemed uniquely an Iranian phenomenon? Or, this integrated multi-layer approach could be successful anywhere? Would such a combination of interventionist approaches be successful only for single mothers, or could this benefit other client groups? The definitive answers to these questions will be provided only after further research and practice by motivated researchers and 
social workers. Our project encourages social work policies that pay attention to cognitive empowerment and try to expand clients’ long term and independent problem-solving capacities through fostering positive learning spaces. “Quick fix” policies and practices can lead to creating clients that become dependent on continuous support from social workers. We encourage a philosophy of practice that empowers people by developing their cognitive skills, and maximizes their capacity to handle problems independently.

\section{Acknowledgments}

The authors would like to thank the participants for their invaluable collaboration and efforts.

\section{References}

Behzisti organization (2008/2011) Behzisti’s instructions, Iran, http://www.behzisti$\underline{\text { kh.ir/index.php?module =subjects \&func=viewpage\&pageid=262 }}$

Brown, G. w. and Moran, P. M. (1997) 'Single mothers, poverty and depression', Psychological Medicine, 27, pp. 21-33.

Cairney, J., Boyle, M., Offord, D. r., and Racine, Y. (2003) 'Stress, social support and depression in single and married mothers', Soc Psychiatry Psychiatr Epidemiol, 38, pp. 442-449.

Campbell, J. (1996) Understanding John Dewey, Chicago, Open Court.

Coady, N., and Lehmann, P. (2008) Theoretical Perspectives for Direct Social Work Practice: A Generalist-Eclectic Approach, New York, Springer Publishing Company.

Daher, M. and Haz, A. M. 'Changing meaning through art: a systematization of a psychosocial intervention with Chilean women in urban poverty situation', American Journal of 
Community Psychology Advance Access published December 24, 2010, doi: 10.1007/s 10464-010-9400-3.

Damasio, A. (2003) Looking for Spinoza: Joy, Sorrow, and the Feeling Brain, New York, Harvest Book.

Dewey, J. (1922/2002) Human Nature and Conduct, New York, Dover Publications, Inc.

Dewey J. (1938/1998) Experience and Education, Indiana, Kappa Delta Pi.

Dziak, E., Janzen, B. L. and Muhajarine, N. 'Inequalities in psychological well-being of employed, single and partnered mothers: the role of psychosocial work quality and workfamily conflict', International Journal for Equity in Health Advance Access published February 22, 2010, doi:10.1186/1475-9276-9-6.

Hayden Tufts, J. (1917) 'The moral life and the construction of values and standards', in Dewey, J. and Webster More, E. (eds), Creative Intelligence: Essays in the Pragmatic Attitude, New York, Henry Holt and Company, PP. 354-408.

Heppner, P. P., Kivlighan, D. M. and Wampold, B. E. (2008) Research Design in Counseling, $3^{\text {rd }}$ edition, Belmont, CA, Thomson Higher Education.

Hepworth, D.H., Rooney, R.H. and Larsen, J.A. (2002) Direct Social Work Practice: Theory and Skill, $6^{\text {th }}$ edition, Pacific Grove, CA, Brooks/Cole.

Iversen, S., Kupfermann, I. and Kandel, E. (2000) 'Emotional states and feelings', in Kandel, E., Schwartz, J. and Jessell, T. (eds), Principles of Neural Science, New York, McGraw-Hill, pp. 982-997.

James, W. (1907/1995) Pragmatism, New York, Dover Publication Inc.

Moula, A. (2003) The tree of knowledge: experiences from a research-circle on solutionfocused working-model, Skriftserie 2003:3, Kalmar, Fokus, Kalmar län. 
Moula, A. (2005) Population Based Empowerment Practice in Immigrant Communities, (Doctoral Dissertation), Linkoping, Sweden, Linköpings University.

Moula, A. (2009) Empowerment-oriented social work, Lund, Studentlitteratur.

Moula, A. (2010) Population Based Empowerment Practice in Immigrant Communities, (Published doctoral dissertation with minor changes), Saarbrucken, Lambert academic publisher.

Moula, A., Timpka, T. and Puddephatt, A. (2009) 'Adult-Adolescent Interaction and Adolescents’ Brain Development: Integrating pragmatism/Interactionism and Neuroscience to Develop a Platform for Research on Adolescents’ Life Regulation', Sociology Compass, 3(1), pp. 118-136.

Patton, M.Q. (2002) Qualitative Research \& Evaluation Methods, London, Sage Publication Inc. Payne, M. (1997) Modern Social Work Theory, London, MacMillan Press.

Pease, B. (2002) 'Rethinking empowerment: a postmodern reappraisal for emancipatory practice', British Journal of Social work, 32, pp. 135-147.

Perlman, H. (1957) Social Casework: A Problem-Solving Process, Chicago, University of Chicago Press.

Perlman, H. (1970) 'Problem-solving model in social case work', in Roberts, R. and Nee, R. (eds), Theories of Social Case Work, Chicago, University of Chicago Press.

Purves, D., Brannon, E. M., Cabeza, R., Huettel, S. A., LaBar, K. S., Platt, M. L., \& Woldorff, M. (2008) Principles of Cognitive Neuroscience, Sunderland, MA, Sinauer Associates Inc. 
Saleebey, D. (2006). The Strengths Perspective in Social Work Practice. Boston: Allyn \& Bacon.

Spalek, B. (2011) 'Editorial', British Journal of Social work, 40, pp. 1662-63.

Statistical centre of Iran, (2011) Women households in Iran; sociodemographic characteristics, Iran, http://amar.sci.org.ir/

Turner, J. and Jaco, R. M. (1996) 'Problem-solving theory and social work treatment', in Turner, F. J. (ed), Social Work Treatment, New York, The Free Press, pp. 503-522.

Wang, J. L. (2004) 'The difference between single and married mothers in the 12-month prevalence of major depressive syndrome, associated factors and mental health service utilization', Soc Psychiatry Psychiatr Epidemiol, 39, pp. 26-32.

Zelazo, P. D., Carter, A., Reznick, J. S. and Frye, D. (1997) 'Early development of executive function: a problem-solving framework', Review of General Psychology, 1(2), pp. 198-226. 